\title{
Convergence Axioms on Dislocated Symmetric Spaces
}

\author{
I. Ramabhadra Sarma, ${ }^{1}$ J. Madhusudana Rao, ${ }^{2}$ P. Sumati Kumari, ${ }^{3}$ and D. Panthi ${ }^{4}$ \\ ${ }^{1}$ Department of Mathematics, Acharya Nagarjuna University, Guntur 522004, India \\ ${ }^{2}$ Department of Mathematics, Vijaya College of Engineering, India \\ ${ }^{3}$ Department of Mathematics, $K$ L University, India \\ ${ }^{4}$ Department of Mathematics, Nepal Sanskrit University, Nepal
}

Correspondence should be addressed to P. Sumati Kumari; mumy143143143@gmail.com

Received 22 July 2014; Accepted 18 August 2014; Published 14 October 2014

Academic Editor: Kyung Soo Kim

Copyright ( 2014 I. Ramabhadra Sarma et al. This is an open access article distributed under the Creative Commons Attribution License, which permits unrestricted use, distribution, and reproduction in any medium, provided the original work is properly cited.

Dislocated symmetric spaces are introduced, and implications and nonimplications among various kinds of convergence axioms are derived.

\section{Introduction}

A metric space is a special kind of topological space. In a metric space, topological properties are characterized by means of sequences. Sequences are not sufficient in topological spaces for such purposes. It is natural to try to find classes intermediate between those of topological spaces and those of metric spaces in which members sequences play a predominant part in deciding their topological properties. A galaxy of mathematicians consisting of such luminaries as Frechet [1], Chittenden [2], Frink [3], Wilson [4], Niemytzki [5], and Aranđelović and Kečkić [6] have made important contributions in this area. The basic definition needed by most of these studies is that of a symmetric space. If $X$ is a nonempty set, a function : $X \times X \rightarrow R^{+}$is called a dislocated symmetric on $X$ if $d(x, y)=0$ implies that $x=y$ and $d(x, y)=d(y, x)$ for all $x, y \in X$. A dislocated symmetric (simply $d$-symmetric) on $X$ is called symmetric on $X$ if $d(x, x)=0$ for all $x$ in $X$. The names dislocated symmetric space and symmetric space have expected meanings. Obviously, a symmetric space that satisfies the triangle inequality is a metric space. Since the aim of our study is to find how sequential properties and topological properties influence each other, we collect various properties of sequences that have been shown in the literature to have a bearing on the problem under study. In what follows " $d$ " denotes a dislocated distance on a nonempty set $X . x_{n}, y_{n}, x, y$, and so forth are elements of $X$ and $C_{i}$ for $1 \leq i \leq 5$ and $W_{i}$ for $1 \leq i \leq 3$ indicate properties of sequences in $(X, d)$. Consider

$$
\begin{aligned}
& C_{1}: \lim d\left(x_{n}, y_{n}\right)=0=\lim d\left(x_{n}, x\right) \Rightarrow \lim d\left(y_{n},\right. \\
& x)=0, \\
& C_{2}: \lim d\left(x_{n}, x\right)=0=\lim d\left(y_{n}, x\right) \Rightarrow \lim d\left(x_{n},\right. \\
& \left.y_{n}\right)=0, \\
& C_{3}: \lim d\left(x_{n}, y_{n}\right)=0=\lim d\left(y_{n}, z_{n}\right) \Rightarrow \lim d\left(x_{n},\right. \\
& \left.z_{n}\right)=0 .
\end{aligned}
$$

A space in which $C_{1}$ is satisfied is called coherent by Pitcher and Chittenden [7]. Niemytzki [5] proved that a coherent symmetric space $(X, d)$ is metrizable, and in fact there is a metric $\rho$ on $X$ such that $(X, d)$ and $(X, \rho)$ have identical topologies and also that $\lim d\left(x_{n}, x\right)=0$ if and only if $\lim \rho\left(x_{n}, x\right)=0$.

Cho et al. [8] have introduced

$$
\begin{aligned}
& C_{4}: \lim d\left(x_{n}, x\right)=0 \Rightarrow \lim d\left(x_{n}, y\right)=d(x, y) \text { for all } \\
& y \text { in } X, \\
& C_{5}: \lim d\left(x_{n}, x\right)=\lim d\left(x_{n}, y\right)=0 \Rightarrow x=y .
\end{aligned}
$$

The following properties were introduced by Wilson [4]:

$W_{1}$ : for each pair of distinct points $a, b$ in $X$ there corresponds a positive number $r=r(a, b)$ such that $r<\inf _{c \in X} d(a, c)+d(b, c)$, 
$W_{2}$ : for each $a \in X$, for each $k>0$, there corresponds a positive number $r=r(a, k)$ such that if $b$ is a point of $X$ such that $d(a, b) \geq k$ and $c$ is any point of $X$ then $d(a, c)+d(c, b) \geq r$

$W_{3}$ : for each positive number $k$ there is a positive number $r=r(k)$ such that $d(a, c)+d(c, b) \geq r$ for all $c$ in $X$ and all $a, b$ in $X$ with $d(a, b) \geq k$.

\section{Implications among the Axioms}

Proposition 1. In a d-symmetric space $(X, d), C_{3} \Rightarrow C_{1} \Rightarrow$ $C_{5}, C_{3} \Rightarrow C_{2}$, and $C_{4} \Rightarrow C_{5}$.

Proof. Assume that $C_{3}$ holds in $(X, d)$ and let $\lim d\left(x_{n}, y_{n}\right)=$ 0 and $\lim d\left(x_{n}, x\right)=0$. Put $z_{n}=x \forall n$ so that

$$
\begin{aligned}
\lim d\left(x_{n}, z_{n}\right) & =\lim d\left(x_{n}, x\right)=0 \\
& =\lim d\left(x_{n}, y_{n}\right)=\lim d\left(y_{n}, x_{n}\right) .
\end{aligned}
$$

By $C_{3}, \lim d\left(y_{n}, z_{n}\right)=0$; that is, $\lim d\left(y_{n}, x\right)=0$.

Hence

$$
C_{3} \Rightarrow C_{1}
$$

Assume that $C_{1}$ holds in $(X, d)$ and let $\lim d\left(x_{n}, x\right)=0$ and $\lim d\left(x_{n}, y\right)=0$. Put $y_{n}=y \forall n$; then

$$
\lim d\left(x_{n}, y_{n}\right)=\lim d\left(x_{n}, x\right)=0
$$

By $C_{1}, \lim d\left(y_{n}, x\right)=0$; that is, $\lim d(y, x)=0$.

Consider $\lim d(x, y)=0$; this implies that $x=y$. Hence $\mathrm{C}_{5}$ holds. Thus

$$
C_{1} \Longrightarrow C_{5}
$$

Assume that $C_{3}$ holds and let $\lim d\left(x_{n}, x\right)=0$ and $\lim d\left(y_{n}, x\right)=0$.

Put $z_{n}=x \forall n$; then $\lim d\left(x_{n}, z_{n}\right)=\lim d\left(z_{n}, y_{n}\right)=0$.

By $C_{3}, \lim d\left(x_{n}, y_{n}\right)=0$. Hence

$$
C_{3} \Longrightarrow C_{2} \text {. }
$$

Assume that $C_{4}$ holds and let $\lim d\left(x_{n}, x\right)=0$ and $\lim d\left(x_{n}, y\right)=0$. $x=y$.

By $C_{4}, \lim d\left(x_{n}, y\right)=d(x, y)$. Hence $d(x, y)=0$. Hence

The following proposition explains the relationship between Wilson's axioms [4] $W_{1}, W_{2}$, and $W_{3}$ and the $C_{i}$ 's.

Proposition 2. Let $(X, d)$ be a d-symmetric space; then

$$
\text { (i) } W_{1} \Leftrightarrow C_{5} \text {, (ii) } W_{2} \Leftrightarrow C_{1} \text {, and (iii) } W_{3} \Leftrightarrow C_{3} \text {. }
$$

Proof. (i) Assume $W_{1}$. Suppose $\lim d\left(a, x_{n}\right)=\lim d\left(b, x_{n}\right)=$ 0 but $a \neq b$.

Then

$$
\lim \left\{d\left(a, x_{n}\right)+d\left(b, x_{n}\right)\right\}=0 \quad \text { but } a \neq b
$$

By

$$
W_{1} \exists r>0 \ni \forall x, \quad d(a, x)+d(b, x) \geq r,
$$

equations (6) and (7) are contradictory. Hence $a=b$. Thus $W_{1} \Rightarrow C_{5}$.

Suppose that $W_{1}$ fails. Then there exist $a \neq b$ in $X$ such that for every $n$ there corresponds $x_{n}$ in $X$ such that $d\left(a, x_{n}\right)+$ $d\left(b, x_{n}\right)<1 / n$ :

$$
\Longrightarrow \lim d\left(a, x_{n}\right)=\lim d\left(b, x_{n}\right)=0 \quad \text { but } a \neq b .
$$

Thus if $W_{1}$ fails then $C_{5}$ fails. That is, $C_{5} \Rightarrow W_{1}$. Hence $W_{1} \Leftrightarrow$ $\mathrm{C}_{5}$.

(ii) Assume $W_{2}$. Then for each $a \in X$ and each $k>0$ there corresponds $r>0$ such that, for all $b \in X$ with $d(a, b) \geq$ $k$ and $\forall x \in X, d(a, x)+d(b, x) \geq r$.

Suppose that $C_{1}$ fails. There exist $a \in X,\left\{b_{n}\right\}$, and $\left\{c_{n}\right\}$ in $X$ such that $\lim d\left(a, b_{n}\right)=\lim d\left(b_{n}, c_{n}\right)=0$ but $\lim d\left(a, c_{n}\right) \neq 0$.

Since $\lim d\left(a, c_{n}\right) \neq 0$ there exists $k>0$ and a subsequence $\left(c_{n_{k}}\right)$ such that

$$
d\left(a, c_{n_{k}}\right)>k \quad \forall n_{k}
$$

Since

$$
d\left(a, c_{n_{k}}\right)>k, \quad d\left(a, b_{n_{k}}\right)+d\left(b_{n_{k}}, c_{n_{k}}\right) \geq r,
$$

this implies that $\lim \left\{d\left(a, b_{n}\right)+d\left(b_{n}, c_{n}\right)\right\} \neq 0$, a contradiction.

Conversely assume that $W_{2}$ fails. Then there exist $a \in X$ and $k>0$ such that $\forall n>0 \exists b_{n} \in X$ and $c_{n} \in X$ such that

$$
d\left(a, b_{n}\right) \geq k \text { but } d\left(a, c_{n}\right)+d\left(b_{n}, c_{n}\right)<\frac{1}{n} .
$$

This implies that $\lim d\left(a, c_{n}\right)=\lim d\left(b_{n}, c_{n}\right)=0$ but $\lim d\left(a, b_{n}\right) \neq 0$.

Hence $C_{1}$ fails.

(iii) Assume $W_{3}$. Suppose that $C_{3}$ fails. Then there exist sequences $\left\{a_{n}\right\},\left\{b_{n}\right\}$, and $\left\{c_{n}\right\}$ in $X$ such that $\lim d\left(a_{n}, b_{n}\right)=$ $\lim d\left(b_{n}, c_{n}\right)=0$ but $\lim d\left(a_{n}, c_{n}\right) \neq 0$.

Since $W_{3}$ holds, $\forall k>0$ there corresponds $r>0$ such that for all $a, b$ with

$$
d(a, b) \geq k, \quad d(a, c)+d(b, c) \geq r \quad \forall c .
$$

Since $\lim d\left(a_{n}, c_{n}\right) \neq 0$ there exists a positive number $\epsilon$ and a subsequence of positive integers $\left\{n_{k}\right\}$ such that $d\left(a_{n_{k}}, c_{n_{k}}\right)>\epsilon$. Choose $r_{1}$ corresponding to $\epsilon$ so that

$$
d\left(a_{n_{k}}, b_{n_{k}}\right)+d\left(b_{n_{k}}, c_{n_{k}}\right) \geq r_{1} \text {. }
$$

Thus

$$
\lim \left\{d\left(a_{n_{k}}, b_{n_{k}}\right)+d\left(b_{n_{k}}, c_{n_{k}}\right)\right\} \neq 0
$$

This contradicts the assumption that $\lim d\left(a_{n}, b_{n}\right)=$ $\lim d\left(b_{n}, c_{n}\right)=0$.

Hence

$$
W_{3} \Longrightarrow C_{3} \text {. }
$$

Assume that $W_{3}$ fails. 
Then there exists $k>0$ such that, $\forall$ positive integer $n$, there exist $a_{n}, b_{n}$, and $c_{n}$ with

$$
d\left(a_{n}, b_{n}\right) \geq k \quad \text { but } d\left(a_{n}, c_{n}\right)+d\left(b_{n}, c_{n}\right)<\frac{1}{n}
$$

Hence

$\lim d\left(a_{n}, b_{n}\right) \neq 0 \quad$ but $\lim d\left(a_{n}, c_{n}\right)=\lim d\left(c_{n}, b_{n}\right)=0$.

Hence $C_{3}$ fails.

Hence

$$
C_{3} \Longrightarrow W_{3} \text {. }
$$

This completes the proof of the proposition.

We introduce the following.

Axiom C. Every convergent sequence satisfies Cauchy criterion. That is, if $\left(x_{n}\right)$ is a sequence in $X, x \in X$ and $\lim d\left(x_{n}, x\right)=0$; then given $\epsilon>0 \exists N(\epsilon) \in \mathbf{N}$ such that $d\left(x_{n}, x_{m}\right)<\epsilon$ whenever $m, n \geq N(\epsilon)$ we have the following.

Proposition 3. In ad-symmetric space $(X, d), C_{1} \Rightarrow C \Rightarrow C_{2}$.

Proof. For $C_{1} \Rightarrow C$, suppose that a sequence $\left(x_{n}\right)$ in $(X, d)$ is convergent to $x$ but does not satisfy Cauchy criterion. Then $\exists r>0$ such that for every positive integer $k$ there correspond integers $m_{k}, n_{k}$ such that

$$
m_{k+1}>n_{k+1}>m_{k}>n_{k}, \quad d\left(x_{m_{k}}, x_{n_{k}}\right)>\gamma \quad \forall k
$$

Let

$$
y_{k}=x_{m_{k}}, \quad z_{k}=x_{n_{k}} \quad \forall k
$$

Then

$$
\lim d\left(y_{k}, x\right)=0, \quad \lim d\left(z_{k}, x\right)=0 .
$$

But $\lim d\left(y_{k}, z_{k}\right) \neq 0$; this contradicts $C_{1}$.

Proof. For $C \Rightarrow C_{2}$, suppose that $\lim d\left(x_{n}, x\right)=\lim d\left(y_{n}\right.$, $x)=0$.

Let $\left(z_{n}\right)$ be the sequence defined by $z_{2 n-1}=x_{n}$ and $z_{2 n}=y_{n}$. Then $\lim d\left(z_{n}, x\right)=0$. Hence $\left(z_{n}\right)$ satisfies Cauchy criterion. $N(\epsilon)$ :

Given $\epsilon>0 \exists N(\epsilon) \in \mathbf{N}$ such that $d\left(z_{n}, z_{m}\right)<\epsilon$ for $m, n \geq$

$$
\begin{aligned}
& \Rightarrow d\left(z_{2 n-1}, z_{2 n}\right)<\epsilon \text { for } n \geq N(\epsilon), \\
& \Rightarrow \lim d\left(x_{n}, y_{n}\right)<\epsilon \text { for } n \geq N(\epsilon), \\
& \Rightarrow \lim d\left(x_{n}, y_{n}\right)=0 .
\end{aligned}
$$

\section{Examples for Nonimplications}

Example 4. A $d$-symmetric space in which the triangular inequality fails and $C_{1}$ through $C_{5}$ hold.

Let $X=[0,1]$. Define $d$ on $X \times X$ as follows:

$$
d(x, y)= \begin{cases}x+y & \text { if } x \neq y \\ 1 & \text { if } x=y \neq 0 \\ 0 & \text { if } x=y=0\end{cases}
$$

Clearly $d$ is a $d$-symmetric space. $d$ does not satisfy the triangular inequality since $d(0.1,0.2)+d(0.2,0.1)=0.6<$ $1=d(0.1,0.1)$.

We show that $C_{1}$ through $C_{5}$ holds. We first show that $\lim d\left(x_{n}, x\right)=0$ iff $x=0$ and $\lim x_{n}=0$ in $R$.

If $x \neq 0$ then $\lim d\left(x_{n}, x\right)=x_{n}+x \geq x>0$. Hence $\lim d\left(x_{n}, x\right) \geq x>0$.

If $x=0$ then $\lim d\left(x_{n}, 0\right)=0$ or $x_{n}$. Hence $\lim d\left(x_{n}, x\right)=$ $0 \Leftrightarrow \lim x_{n}=0$ in $R$.

Now we show that $\lim d\left(x_{n}, y_{n}\right)=0$ if and only if $\lim x_{n}=$ $\lim y_{n}=0$ in $R$.

Consider $\lim d\left(x_{n}, y_{n}\right)=0 \Rightarrow d\left(x_{n}, y_{n}\right)<1 / 2$ for large $n$ :

$$
\begin{aligned}
& \Rightarrow d\left(x_{n}, y_{n}\right)=x_{n}+y_{n} \text { or } 0 \text { for large } n, \\
& \Rightarrow \text { either } x_{n}=y_{n}=0 \text { or } d\left(x_{n}, y_{n}\right)=x_{n}+y_{n} \text { for large } \\
& n, \\
& \Rightarrow \lim x_{n}=\lim y_{n}=0 \text { in } R .
\end{aligned}
$$

Conversely if $\lim x_{n}=\lim y_{n}=0$ in $R$ then $\lim d\left(x_{n}, y_{n}\right)=$ 0 or $x_{n}+y_{n}$ for large $n$.

Hence $\lim d\left(x_{n}, y_{n}\right)=0$.

Verification of validity of $C_{1}$ through $C_{5}$ is done as follows.

$C_{1}$ : let $\lim d\left(x_{n}, y_{n}\right)=0$ and $\lim d\left(x_{n}, x\right)=0$; then $\lim x_{n}=\lim y_{n}=0$ in $R$ and $x=0$.

Hence $d\left(y_{n}, x\right)=d\left(y_{n}, 0\right)=y_{n}$ or 0 . This implies that $\lim d\left(y_{n}, x\right)=0$.

$C_{2}$ : let $d\left(x_{n}, x\right)=d\left(y_{n}, x\right)=0$. Then $x=0$ and $\lim x_{n}=$ $\lim y_{n}=0$ in $R$.

Hence $\lim d\left(y_{n}, x_{n}\right)=0$.

$C_{3}$ : let $d\left(x_{n}, y_{n}\right)=d\left(y_{n}, z_{n}\right)=0$; then $\lim x_{n}=\lim y_{n}=$ $\lim z_{n}=0$ in $R$.

Hence $\lim d\left(x_{n}, z_{n}\right)=0$.

$C_{4}$ : let $\lim d\left(x_{n}, x\right)=0$. Then $x=0$ and $\lim x_{n}=0$.

If $y=0,0 \leq d\left(x_{n}, y\right) \leq x_{n}$. Hence $\lim d\left(x_{n}, y\right)=0=$ $d(x, y)$.

If $y \neq 0, d\left(x_{n}, y\right)=x_{n}+y$. Hence $\lim d\left(x_{n}, y\right)=y=$ $0+y=d(x, y)$.

$C_{5}$ : let $\lim d\left(x_{n}, x\right)=0$ and $\lim d\left(x_{n}, y\right)=0$.

Then $x=0, y=0$ and $\lim x_{n}=0$. Hence $x=y$.

Example 5. A $d$-symmetric space $(X, d)$ in which $C_{1}$ [hence $C_{5}$ ] holds while $C_{j}$ does not hold for $j=2,3,4$. 
Let $X=[0, \infty)$. Define $d$ on $X \times X$ as follows:

$$
d(x, y)= \begin{cases}x+y & \text { if } x \neq 0 \neq y \\ \frac{1}{x} & \text { if } x \neq 0=y \\ \frac{1}{y} & \text { if } x=0 \neq y \\ 0 & \text { if } x=0=y\end{cases}
$$

Clearly $(X, d)$ is a $d$-symmetric space. We show that $C_{1}, C_{5}$ hold.

Let $\lim d\left(x_{n}, x\right)=0=\lim d\left(x_{n}, y_{n}\right)$.

If $x \neq 0, d\left(x_{n}, x\right)>x$ if $x_{n} \neq 0$.

$$
=\frac{1}{x} \text { if } x_{n}=0
$$

This implies that

$$
\lim d\left(x_{n}, x\right) \geq \min \left\{x, \frac{1}{x}\right\}>0
$$

Thus $\lim d\left(x_{n}, x\right)=0 \Rightarrow x=0$ and $\left(x_{n}\right)$ can be split into two subsequences $\left(x_{n}{ }^{(1)}\right),\left(x_{n}{ }^{(2)}\right)$, where $\left(x_{n}{ }^{(1)}\right)=0 \forall n,\left(x_{n}{ }^{(2)}\right) \neq$ 0 for every $n$ and if $\left(x_{n}{ }^{(2)}\right)$ is infinite subsequence $\lim \left(x_{n}{ }^{(2)}\right)=$ $\infty$. We consider the case where both $\left(x_{n}{ }^{(1)}\right)$ and $\left(x_{n}{ }^{(2)}\right)$ are infinite sequences as when one is a finite sequence the same proof works with minor modifications. Consider

$$
\begin{aligned}
\lim d\left(x_{n}, y_{n}\right) & =0 \Longrightarrow \lim d\left(x_{n}{ }^{(1)}, y_{n}{ }^{(1)}\right) \\
& =\lim d\left(x_{n}{ }^{(2)}, y_{n}{ }^{(2)}\right)=0 .
\end{aligned}
$$

If we show that $y_{n}{ }^{(2)}$ cannot be positive for infinitely many $n$, it will follow that $\lim d\left(x_{n}{ }^{(2)}, y_{n}{ }^{(2)}\right)=\lim d\left(x_{n}{ }^{(2)}, 0\right)=0$ so that $\lim d\left(0, y_{n}\right)=0$. Hence $C_{1}$ holds.

If $y_{n}{ }^{(2)} \neq 0$ for infinitely many $n$, say $\left\{y_{n_{k}}{ }^{(2)}\right\}$ is the infinite subsequence of $\left\{y_{n}{ }^{(2)}\right\}$ with $y_{n_{k}}{ }^{(2)} \neq 0 \forall n_{k}$, then $d\left(x_{n_{k}}{ }^{(2)}, y_{n_{k}}{ }^{(2)}\right)=x_{n_{k}}{ }^{(2)}+y_{n_{k}}{ }^{(2)}>x_{n_{k}}{ }^{(2)}$ so that $\lim d\left(x_{n_{k}}{ }^{(2)}, y_{n_{k}}{ }^{(2)}\right) \geq \lim x_{n_{k}}{ }^{(2)} \geq \infty$ contradicting the assumption that $\lim d\left(x_{n}, y_{n}\right)=0$. Thus $C_{1}$ holds. Since $C_{1} \Rightarrow C_{5}, C_{5}$ holds.

$C_{2}$ does not hold since $d(n, 0)=1 / n$ while $d(n, n)=$ $2 n \forall n$ so that $\lim d(n, n) \neq 0$.

$C_{3}$ does not hold since $\lim d(n, 0)=\lim d(0, n)$ while $\lim d(n, n)=\infty$.

$C_{4}$ does not hold since $\lim d(n, 0)=0$ but $\lim d(n, 2)=\infty$ while $d(0,2)=1 / 2$.

Example 6. A $d$-symmetric space $(X, d)$ in which $C_{2}$ holds but $C_{1}, C_{3}, C_{4}$, and $C_{5}$ fail.
Let $X=[0,1] \cup\{2\}$. Define $d$ on $X \times X$ as follows:

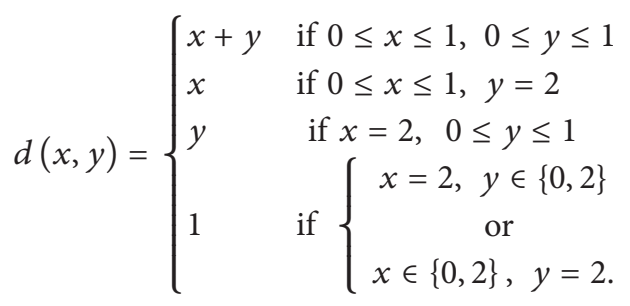

Clearly $(X, d)$ is a $d$-symmetric space.

We first show that if $\left\{x_{n}\right\}$ in $X$ converges to $x$ in $(X, d)$ then $x \in\{0,2\}$.

Suppose that $x \neq 0$ and $x \neq 2$; then $x \in(0,1]$ :

$$
\begin{aligned}
& \Rightarrow \lim d\left(x_{n}, x\right)=0=x_{n}+x \text { or } x, \\
& \Rightarrow \lim d\left(x_{n}, x\right) \geq x>0, \\
& \Rightarrow \lim d\left(x_{n}, x\right) \neq 0 .
\end{aligned}
$$

Hence if $\lim d\left(x_{n}, x\right)=0$ then $x \in\{0,2\}$.

$C_{1}$ fails: $x_{n}=1 / n, y_{n}=2$, and $x=0$;

$$
\begin{gathered}
d\left(x_{n}, y_{n}\right)=\frac{1}{n}, \quad d\left(x_{n}, x\right)=\frac{1}{n}, \quad d\left(y_{n}, x\right)=1 \\
\Longrightarrow \lim d\left(x_{n}, y_{n}\right)=0=d\left(x_{n}, x\right) \quad \text { but } \lim d\left(y_{n}, x\right) \neq 0 .
\end{gathered}
$$

$C_{2}$ holds: suppose that $\lim d\left(x_{n}, x\right)=\lim d\left(y_{n}, x\right)=$ 0 ; then $x \in\{0,2\}$.

Case 1. If $x=2, \lim d\left(x_{n}, x\right) \rightarrow 0 \Rightarrow d\left(x_{n}, x\right)=x_{n}$ eventually and $\lim x_{n}=0$ in $R$. Hence $\exists N \in \mathbf{N} \ni x_{n}<1$ and $y_{n}<1$ for $n \geq N$. 0 .

Here $d\left(x_{n}, y_{n}\right)=x_{n}+y_{n}$. This implies that $\lim d\left(x_{n}, y_{n}\right)=$

Case 2. If $x=0$,

$$
d\left(x_{n}, 0\right)= \begin{cases}1 & \text { if } x_{n}=2 \text { or } 0 \\ x_{n} & \text { if } 0 \leq x_{n} \leq 1\end{cases}
$$
0 in $R$.

If $\lim d\left(x_{n}, 0\right)=0, d\left(x_{n}, 0\right)=x_{n}$ eventually and $\lim x_{n}=$

Similarly $d\left(y_{n}, 0\right)=y_{n}$ eventually and $\lim y_{n}=0$ in $R$.

As in Case 1 it follows that

$$
\lim d\left(x_{n}, y_{n}\right)=\lim \left(x_{n}+y_{n}\right)=0 .
$$

Thus $C_{2}$ holds.

$$
\begin{aligned}
& C_{3} \text { fails since } C_{3} \Rightarrow C_{1} . \\
& C_{5} \text { fails: let } x_{n}=1 / n, x=0 \text {, and } y=2 \\
& \lim d\left(x_{n}, 0\right)=\lim \left(\frac{1}{n}\right)=0=\lim d\left(x_{n}, 2\right) \\
& C_{4} \text { fails since } C_{4} \Rightarrow C_{5} .
\end{aligned}
$$


Example 7. Ad-symmetric space $(X, d)$ in which $C_{4}$ holds but $C_{1}$ fails.

Let $X=N \cup\{0\}$. Define $d$ on $X \times X$ as follows:

$$
\begin{aligned}
& d(m, n)=d(n, m) \quad \forall m, n \in X, \\
& d(0, n)= \begin{cases}\frac{1}{n} & \text { if } n \text { is odd } \\
1 & \text { if } n \text { is even, }\end{cases} \\
& d(0,0)=0,
\end{aligned}
$$$$
d(m, n)= \begin{cases}\left|\frac{1}{m}-\frac{1}{n}\right| & \text { if } m+n \text { is even } \\ 1 & \text { or } m+n \text { is odd and }|m-n|=1, \\ \text { if } m+n \text { is odd and }|m-n|>2 .\end{cases}
$$

If $\left\{x_{n}\right\}$ in $X$ and $\lim d\left(x_{n}, 0\right)=0$ then $x_{n}$ is eventually odd.

If $x \neq 0, d\left(x_{n}, x\right)$ cannot be 1 so $x_{n}+x$ is even or odd and $\left|x_{n}-x\right|=1$.

0 .

But in this case $d\left(x_{n}, x\right)=\left|1 / x_{n}-1 / x\right|$ so that $d\left(x_{n}, x\right) \neq$

Thus $d\left(x_{n}, x\right)=0 \Leftrightarrow x=0$ and $x_{n}$ is eventually odd.

If $m$ is a fixed even integer and $x_{n}$ is odd, $x_{n}+m$ is odd and eventually $>2$.

So

$$
\lim d\left(x_{n}, m\right)=1=d(0, m) .
$$

If $m$ is a fixed odd integer and $x_{n}$ is odd, $x_{n}+m$ is even.

So $d\left(x_{n}, m\right)=\left|1 / m-1 / x_{n}\right|$ so that $\lim d\left(x_{n}, 0\right)=0 \Rightarrow$ $\lim d\left(x_{n}, m\right)=d(0, m)$.

If $m=0$ and $x_{n}$ is odd eventually

$$
d\left(x_{n}, 0\right)=\frac{1}{n} \quad \text { so } \lim d\left(x_{n}, m\right)=\lim \frac{1}{n}=0=d(0, m) .
$$

If $m=0$ and $x_{n}=0$ eventually

$$
d\left(x_{n}, 0\right)=\frac{1}{n} \quad \text { so } \lim d\left(x_{n}, m\right)=\lim \frac{1}{n}=0=d(0, m) .
$$

Hence $C_{4}$ holds in $(X, d)$.

$C_{1}$ does not hold: let $x_{n}=2 n-1$ and $y_{n}=2 n$ :

$$
\begin{gathered}
d\left(x_{n}, 0\right)=\frac{1}{2 n-1}, \quad d\left(x_{n}, y_{n}\right)=\frac{1}{2 n-1}-\frac{1}{2 n}, \\
d\left(y_{n}, 0\right)=1 .
\end{gathered}
$$

Hence $d\left(x_{n}, 0\right)=d\left(x_{n}, y_{n}\right)=0$ and $d\left(y_{n}, 0\right) \neq 0$.

Example 8. A $d$-symmetric space $(X, d)$ in which $C_{3}$ holds but $C_{4}$ does not hold.
Let $X=[0,1] \cup\{2\}$. Define $d$ on $X \times X$ as follows:

$$
d(x, y)= \begin{cases}x+y & \text { if } 0 \leq x \neq y \leq 1, \\ 1 & \text { if } x=y \neq 0 \text { or } x=y=2 \\ 2 & \text { or } x \in(0,1] \text { and } y=2, \\ 0 & \text { if } x=0 \& y=2 \text { or } x=2 \text { and } y=0,\end{cases}
$$

Clearly $(X, d)$ is a $d$-symmetric space which is not a symmetric space.

We first show that if $\left\{x_{n}\right\}$ converges to $x$ in $(X, d)$ then $x \in\{0,2\}$.

Suppose that $0 \neq x \neq 2$; then $x \in(0,1]$ :

$$
\Longrightarrow d\left(x, x_{n}\right)= \begin{cases}x+x_{n} & \text { if } 0<x \neq x_{n} \leq 1, \\ 1 & \text { if } x=x_{n} \neq 0 \\ & \text { or } x_{n}=2 \text { or } x \in(0,1] \\ & \text { and } x_{n}=2 .\end{cases}
$$

Since $\lim d\left(x, x_{n}\right)=0 \exists N \ni d\left(x, x_{n}\right)<1$ for $n \geq N$

$$
\begin{aligned}
& \Rightarrow d\left(x, x_{n}\right)=x+x_{n} \geq x \text { for } n \geq N, \\
& \Rightarrow \lim d\left(x, x_{n}\right) \neq 0, \text { a contradiction. }
\end{aligned}
$$

We now show that $\lim d\left(x_{n}, y_{n}\right)=0$ if and only if $\lim x_{n}=$ $\lim y_{n}=0$. Consider

$$
\begin{aligned}
& \lim d\left(x_{n}, y_{n}\right) \\
& =0 \Longrightarrow \exists N \in \mathbf{N} \ni d\left(x_{n}, y_{n}\right)<1 \quad \text { for } n \geq N \\
& \Longrightarrow \lim d\left(x_{n}, y_{n}\right)=x_{n}+y_{n} \quad \text { or } \quad 0 \quad \text { for } n \geq N \\
& \Longrightarrow \text { either } x_{n}=y_{n}=0 \quad \text { or } d\left(x_{n}, y_{n}\right)=x_{n}+y_{n}
\end{aligned}
$$

for $n \geq N$

$\Longrightarrow \lim x_{n}=\lim y_{n}=0$.

Conversely if $\lim x_{n}=\lim y_{n}=0$ then $\exists N \in \mathbf{N} \ni x_{n}<$ $1, y_{n}<1$ for $n \geq N \Rightarrow \lim d\left(x_{n}, y_{n}\right)=0$ or $x_{n}+y_{n}$ for large $n$.

Hence $d\left(x_{n}, y_{n}\right)=0$.

Thus $d\left(x_{n}, y_{n}\right)=0$ if and only if $\lim x_{n}=\lim y_{n}=0$.

As a consequence we have

$\lim d\left(x_{n}, y_{n}\right)=0=\lim d\left(y_{n}, z_{n}\right) \Longrightarrow \lim d\left(x_{n}, z_{n}\right)=0$.

Hence $C_{3}$ holds in $(X, d)$.

$C_{4}$ fails: $x_{n}=1 /(n+1)$ for $n \geq 1$ :

$$
d\left(x_{n}, 0\right)=\frac{1}{n+1} \Longrightarrow \lim d\left(x_{n}, 0\right)=0,
$$

$$
d\left(x_{n}, 2\right)=1 \quad \forall n \Longrightarrow \lim d\left(x_{n}, 2\right)=1 \quad \text { but } d(0,2)=2 \text {. }
$$

Example 9. A $d$-symmetric space $(X, d)$ in which $C_{4}$ holds but $C_{2}, C_{3}$ fail to hold. 
Let $X=N \cup\{0, \infty\}$. Define $d$ on $X \times X$ as follows:

$$
\begin{gathered}
d(m, \infty)=d(\infty, m)=1 \quad \text { if } m \in X, \\
d(m, 0)=d(0, m)=\frac{1}{m} \quad \text { if } m \in N, \\
d(0,0)=0 .
\end{gathered}
$$

If $m, n \in N$,

$$
d(m, n)= \begin{cases}\left|\frac{1}{m}-\frac{1}{n}\right| & \text { if }|m-n| \geq 2 \\ 1 & \text { if }|m-n| \leq 1\end{cases}
$$

Clearly $(X, d)$ is a $d$-symmetric space which is not a symmetric space.

We show that if $\lim d\left(x_{n}, x\right)=0$ then $x=0$ and $\left\{x_{n}\right\}$ consists of two subsequences $\left\{y_{n}\right\}$ and $\left\{z_{n}\right\}$, one of which may possibly be finite, where $y_{n}=0 \forall n$ and $0 \neq z_{n} \in N \forall n$ and $\lim \left(1 / z_{n}\right)=0$ (in case $\left\{z_{n}\right\}$ is an infinite sequence).

To prove this we first note that $\lim d\left(x_{n}, x\right)=0 \Rightarrow x \neq \infty$ and $x_{n} \neq \infty$ eventually.

If $x \in N, d\left(x_{n}, x\right)=1 / x$ or 1 or $\left|1 / x_{n}-1 / x\right|$.

Hence $\lim d\left(x_{n}, x\right)=0 \Rightarrow x \notin N$; hence $x=0$.

Further $d\left(x_{n}, 0\right)=0$ or $1 / x_{n}$. Consequently $\left\{x_{n}\right\}$ may be split into two sequences $\left\{y_{n}\right\}$ and $\left\{z_{n}\right\}$ as described above.

We show that $C_{4}$ holds. Assume that $\lim d\left(x_{n}, x\right)=0$. Then $x=0$. $1 / m$.

Let $m \in N$ and $y_{n}=0 \forall n$. Then $d\left(y_{n}, m\right)=d(o, m)=$

So $\lim d\left(y_{n}, m\right)=d(o, m)$.

If $z_{n} \neq 0 \forall n$, and $\lim \left(1 / z_{n}\right)=0$ the $d\left(z_{n}, m\right)=\mid 1 / z_{n}-$ $1 / m \mid$ for $n>m$ so that $\lim d\left(z_{n}, m\right)=1 / m=d(0, m)$.

Thus if $m \in N$ and $\lim d\left(x_{n}, x\right)=0$ then $\lim d\left(x_{n}, m\right)=$ $d(x, m)$.

Clearly this holds when $m=\infty$ or $m=0$ as well.

Hence $C_{4}$ holds.

$C_{2}$ does not hold: let $x_{n}=x, y_{n}=n+1$, and $x=0$ :

$$
\begin{gathered}
d\left(x_{n}, x\right)=d(n, 0)=\frac{1}{n}, \quad \text { hence } \lim d\left(x_{n}, x\right)=0, \\
d\left(y_{n}, x\right)=d(n+1,0)=\frac{1}{n+1}, \text { hence } \lim d\left(y_{n}, x\right)=0, \\
\lim d\left(x_{n}, y_{n}\right)=\lim d(n, n+1) \Longrightarrow \lim d\left(x_{n}, y_{n}\right) \neq 0 .
\end{gathered}
$$

$C_{3}$ does not hold:

$$
\begin{gathered}
x_{n}=n, \quad y_{n}=n+2, \quad z_{n}=x_{n} \\
d\left(x_{n}, y_{n}\right)=d(n, n+2)=\left|\frac{1}{n+2}-\frac{1}{n}\right|=\frac{1}{n}-\frac{1}{n+2} \\
d\left(y_{n}, z_{n}\right)=d\left(x_{n}, y_{n}\right)=\frac{1}{n}-\frac{1}{n+2} \\
\lim d\left(x_{n}, z_{n}\right)=\lim d(n, n)=1
\end{gathered}
$$

$\lim d\left(x_{n}, y_{n}\right)=\lim d\left(y_{n}, z_{n}\right)=0 \quad$ but $\lim d\left(x_{n}, z_{n}\right)=1$.

$C_{5}$ holds since $C_{4} \Rightarrow C_{5}$.
Remarks. From this example we can conclude that

(1) $C_{5}$ does not imply $C_{2}$ as otherwise, since $C_{4} \Rightarrow C_{5}$ it would follow that $C_{4} \Rightarrow C_{2}$ which does not hold as is evident from the above example,

(2) in a $d$-symmetric space, convergent sequences are necessarily Cauchy sequences.

Example 10. A $d$-symmetric space $(X, d)$ in which $C_{4}$ holds but $C_{2}, C_{3}$ fail to hold.

Let $X=N \cup\{0\}$. Define $d$ on $X \times X$ as follows:

$$
\begin{gathered}
d(x, y)=d(y, x)=1 \quad \text { for every } x, y \in X, \\
d(2 m, 0)=1, \\
\left.d(2 m-1,0)=\frac{1}{2 m-1} \quad \forall m, 0\right)=0, \\
d(m, n)= \begin{cases}\frac{1}{m}+\frac{1}{n} & \text { if } m+n \text { is even or }|m-n|=1, \\
\frac{1}{2} & \text { if } m+n \text { is odd and }|m-n|>2 .\end{cases}
\end{gathered}
$$

Clearly $(X, d)$ is a $d$-symmetric space.

We first characterize all convergent sequences in $(X, d)$.

Suppose that $\lim d\left(x_{n}, x\right)=0$. We show that $x=0$.

If $x$ is odd and $x_{n}$ is even $d\left(x_{n}, x\right)=1$ if $x_{n}>x+2$.

So $\lim d\left(x_{n}, x\right) \neq 0$. Thus $x_{n}$ is even for at most finitely many $n$.

We may thus assume that $x_{n}$ is odd $\forall n$.

The $d\left(x_{n}, x\right)=1 / x_{n}+1 / x$ so that $d\left(x_{n}, x\right) \geq 1 / x>0$.

Hence $x$ cannot be odd. Now suppose that $x>0$ and $x$ is even.

Then $d\left(x_{n}, x\right)=1$ if $x_{n}=0$ if $x_{n}$ is odd and $\left|x_{n}-x\right|>$ 2 while $d\left(x_{n}, x\right)=1 / x_{n}+1 / x$ if $x_{n}+x$ is even or $\left|x_{n}-x\right|=1$. In all cases $\lim d\left(x_{n}, x\right) \neq 0$.

Hence the only possibility is $x=0$.

We now show that the following are equivalent.

(a) $\lim d\left(x_{n}, x\right)=0$ in $R$,

(b) there exists a positive integer $N$ such that $x_{n}$ is positive and even, only if $n<N$.

Assumption (b): $x_{n}$ is odd or zero if $n \geq N$ so that $\lim d\left(x_{n}, 0\right)=\lim \left(1 / x_{n}\right)=0$.

Hence $(\mathrm{b}) \Rightarrow(\mathrm{a})$.

Assumption (a): since $d(2 m, 0)=1$ for $m \in N$, it follows that at most finitely many terms of $\left\{x_{n}\right\}$ can be even. This proves (b). Thus $\lim d\left(x_{n}, x\right)=0 \Leftrightarrow x=0$ and $\exists N \in \mathbf{N} \ni x_{n}$ is " 0 " or odd for $n \geq N$.

Consequently $C_{5}$ holds.

$C_{1}$ does not hold: let $x_{n}=2 n+1, y_{n}=2 n$ and $x=0$;

$$
\lim d\left(x_{n}, x\right)=\lim \frac{1}{2 n+1}=0,
$$

$$
\lim d\left(x_{n}, y_{n}\right)=\lim \frac{1}{2 n+1}+\frac{1}{2 n}=0 .
$$

But $\lim d\left(y_{n}, x\right)=1$ since $\lim d(2 n, 0)=1 \forall n$. 
$C_{2}$ holds: assume that $\lim d\left(x_{n}, x\right)=0=\lim d\left(y_{n}, x\right)$.

Then $x=0$ and then there exists $N$ such that $x_{n}$ is " 0 " or odd and $y_{n}=0$ or odd for $n \geq N$ and $\lim \left(1 / x_{n}\right)=$ $\lim \left(1 / y_{n}\right)=0$.

If $x_{n}=y_{n}=0, d\left(x_{n}, y_{n}\right)=0$.

If $x_{n}=0, y_{n}$ is odd, $d\left(x_{n}, y_{n}\right)=1 / y_{n}$.

If $y_{n}=0, x_{n}$ is odd, $d\left(x_{n}, y_{n}\right)=1 / x_{n}$.

If $x_{n}$ is odd and $y_{n}$ is odd, $d\left(x_{n}, y_{n}\right)=1 / x_{n}+1 / y_{n}$.

Consequently $\lim d\left(x_{n}, y_{n}\right)=0$.

$C_{3}$ does not hold: let $x_{n}=0, y_{n}=2 n+1$, and $z_{n}=2 n$ :

$$
\begin{gathered}
d\left(x_{n}, y_{n}\right)=\frac{1}{2 n+1}, \quad d\left(y_{n}, z_{n}\right)=\frac{1}{2 n+1}+\frac{1}{2 n}, \\
d\left(x_{n}, z_{n}\right)=1
\end{gathered}
$$

so that $\lim d\left(x_{n}, y_{n}\right)=\lim d\left(y_{n}, z_{n}\right)=0$ but $\lim d\left(x_{n}, z_{n}\right)=1$.

$C_{4}$ does not hold: let $x_{n}=2 n+1, x=0$, and $y=3$ :

$$
\begin{gathered}
\lim d\left(x_{n}, 0\right)=\lim \frac{1}{2 n+1}=0, \\
\lim d\left(x_{n}, 3\right)=1, \quad \lim d(0,3)=\frac{1}{3} .
\end{gathered}
$$

Example 11. The following example shows that there exist symmetric spaces in which $C$ does not hold.

Let $X=\{0,1 / 2,1 / 3,1 / 4, \ldots\}$.

Define $d(x, x)=0, d(x, y)=d(y, x)$

$$
\begin{gathered}
d\left(\frac{1}{n}, 0\right)=d\left(0, \frac{1}{n}\right)=\frac{1}{n} \quad \forall n \text { in } N, \\
d\left(\frac{1}{n}, \frac{1}{m}\right)=1 \quad \forall n, m \text { in } N .
\end{gathered}
$$

Then $(X, d)$ is a symmetric space; $\{1 / n\}$ converges to 0 but is not a Cauchy sequence.

\section{Disclosure}

Professor I. Ramabhadra Sarma is a retired professor from Acharya Nagarjuna University.

\section{Conflict of Interests}

The authors declare that there is no conflict of interests regarding the publication of this paper.

\section{Acknowledgments}

The authors thank the editor and anonymous referees for their constructive comments, suggestions, and ideas which helped them to improve the paper.

\section{References}

[1] C. F. Frechet, "Sur quelques points du calcul fonctionnel," Rendiconti del Circolo Matematico di Palermo, vol. 22, no. 1, pp. 1-72, 1906.
[2] E. W. Chittenden, "On the equivalence of ecart and voisinage," Transactions of the American Mathematical Society, vol. 18, no. 2, pp. 161-166, 1917.

[3] C. A. H. Frink, "Distance functions and the metrication problem," Bulletin of the American Mathematical Society, vol. 43, 1937.

[4] W. A. Wilson, "On semi-metric Spaces," The American Journal of Mathematics, vol. 53, no. 2, pp. 361-373, 1931.

[5] V. W. Niemytzki, "On the "third axiom of metric space"', Transactions of the American Mathematical Society, vol. 29, no. 3, pp. 507-513, 1927.

[6] I. D. Aranđelović and D. J. Kečkić, "Symmetric spaces approach to some fixed point results," Nonlinear Analysis: Theory, Methods \& Applications, vol. 75, no. 13, pp. 5157-5168, 2012.

[7] A. D. Pitcher and E. W. Chittenden, "On the foundations of the calcul fonctionnel of Fréchet," Transactions of the American Mathematical Society, vol. 19, no. 1, pp. 66-78, 1918.

[8] S. Cho, G. Lee, and J. Bae, "On coincidence and fixed-point theorems in symmetric spaces," Fixed Point Theory and Applications, vol. 2008, Article ID 562130, 9 pages, 2008. 


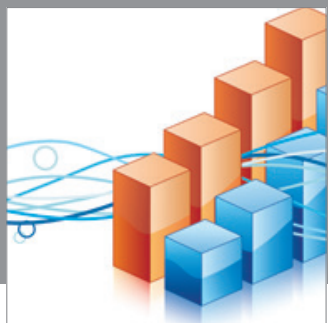

Advances in

Operations Research

mansans

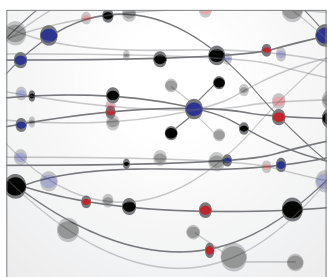

The Scientific World Journal
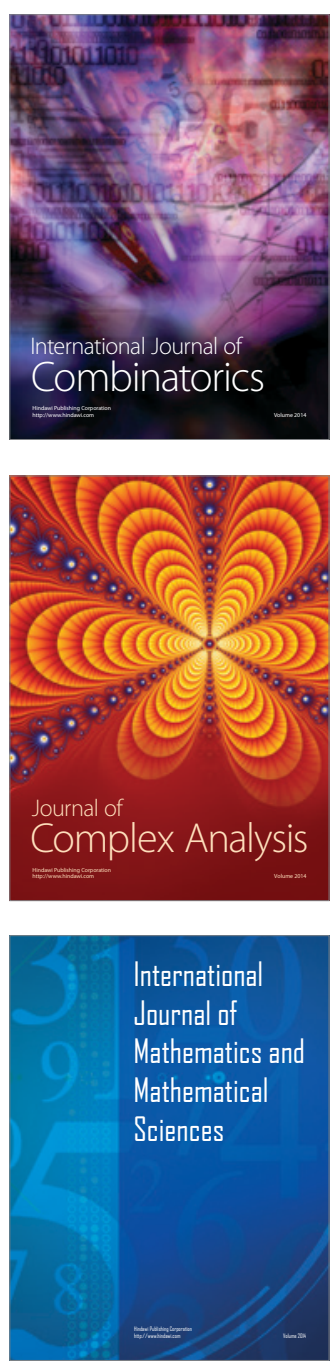
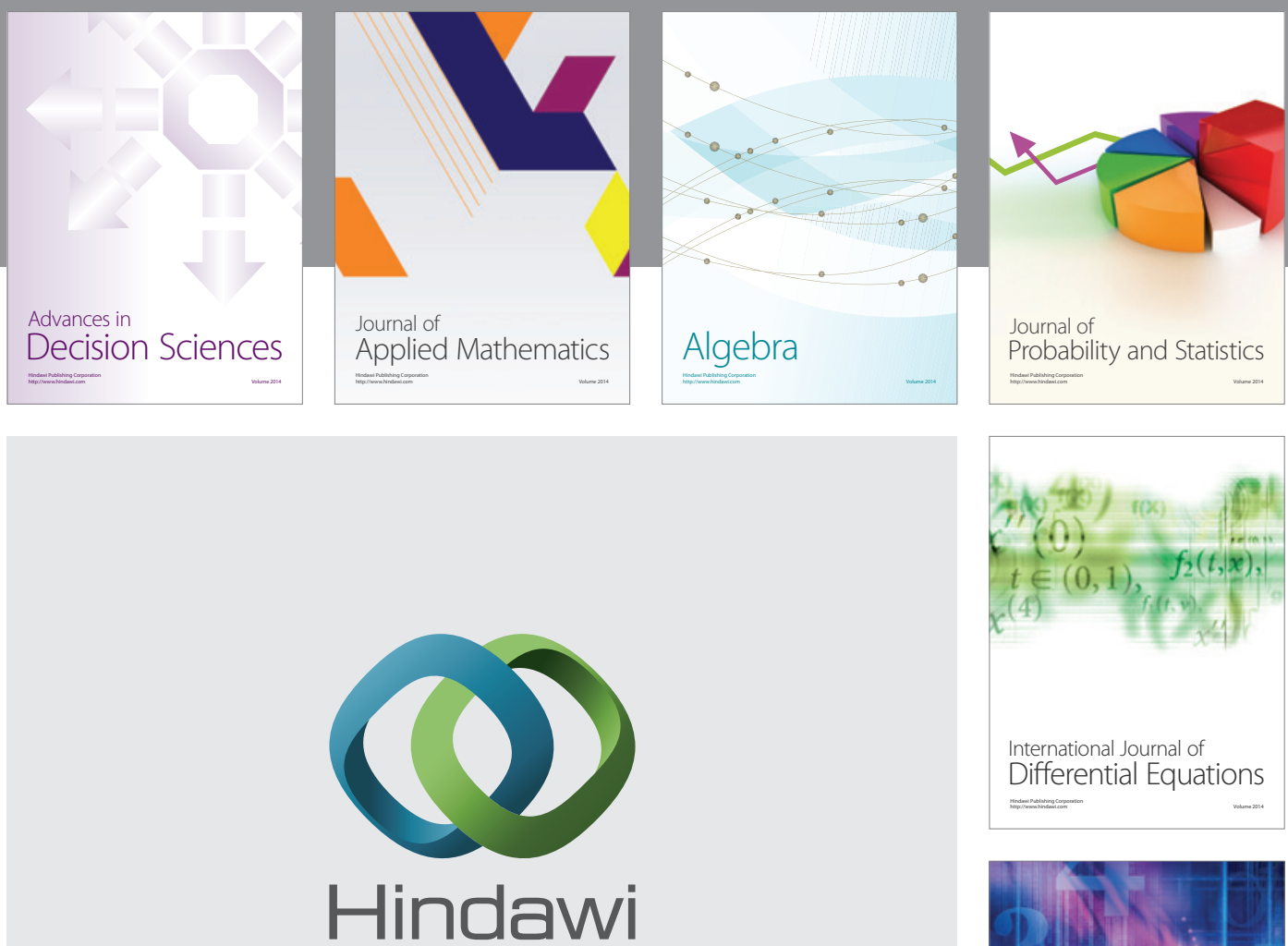

Submit your manuscripts at http://www.hindawi.com
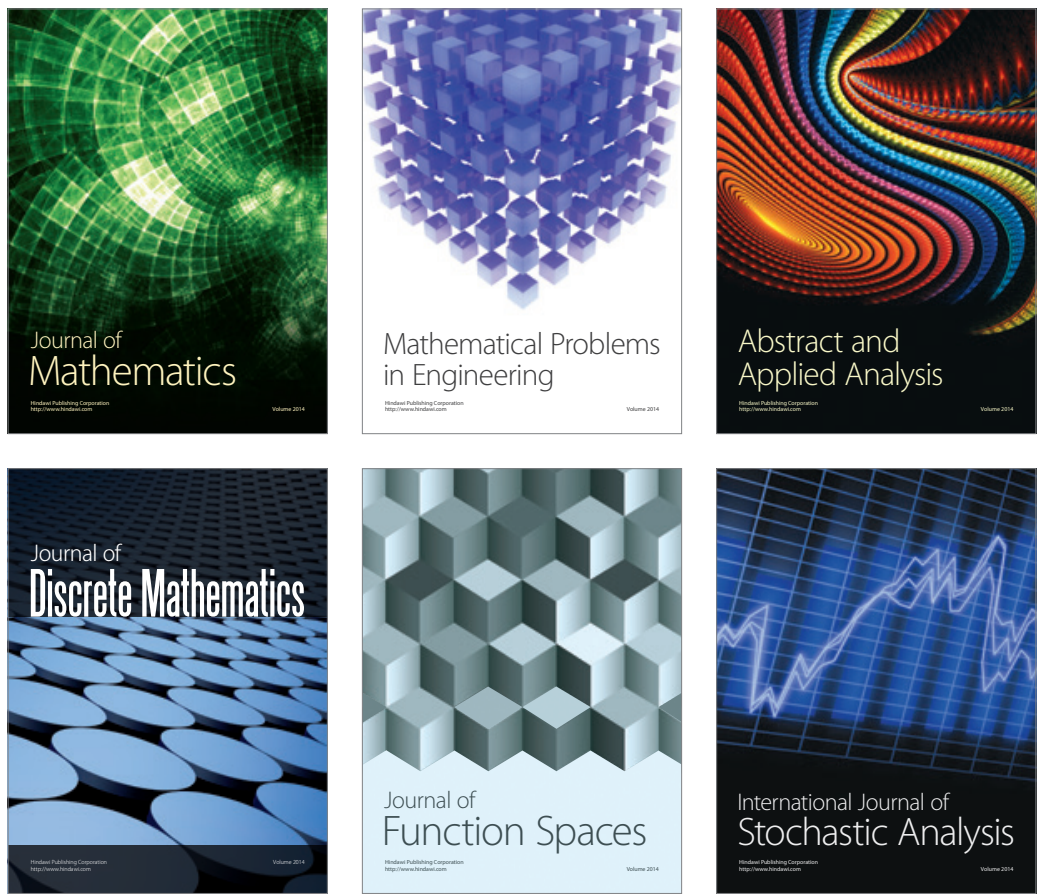

Journal of

Function Spaces

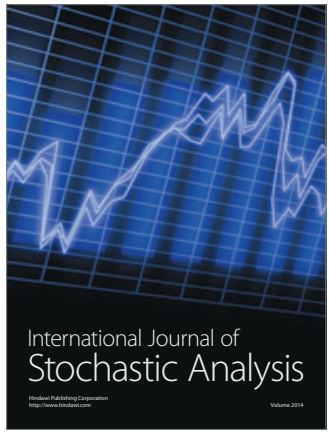

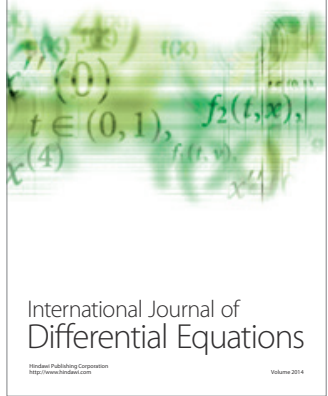
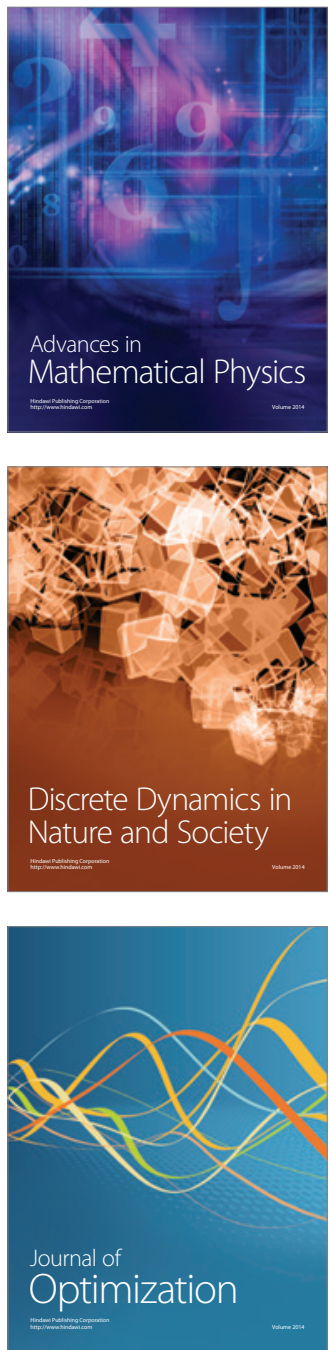